\title{
A randomized clinical trial on the effectiveness of an intervention to treat psychological distress and improve quality of life after autologous stem cell transplantation
}

\author{
Annemarie M. J. Braamse ${ }^{1,2}$ • B. van Meijel ${ }^{1,2,3}$ - O. J. Visser ${ }^{4}$ A. D. Boenink ${ }^{1}$. \\ P. Cuijpers ${ }^{5}$ - C. E. Eeltink ${ }^{4}$ - A. W. Hoogendoorn ${ }^{1}$ - M. van Marwijk Kooy ${ }^{6}$. \\ P. van Oppen ${ }^{1}$ - P. C. Huijgens ${ }^{4}$ - A. T. F. Beekman ${ }^{1}$ • J. Dekker ${ }^{1,7}$
}

Received: 5 January 2015 / Accepted: 13 September 2015 /Published online: 30 September 2015

(C) The Author(s) 2015. This article is published with open access at Springerlink.com

\begin{abstract}
Psychological distress contributes to impaired quality of life in hematological cancer patients. Stepped care treatment, in which patients start with the least intensive treatment most likely to work and only receive more intensive interventions if needed, could improve distress. We aimed to evaluate the outcome of stepped care treatment on psychological distress and physical functioning in patients treated with autologous stem cell transplantation for hematological malignancies. In the present study, we performed a randomized clinical trial with two treatment arms: stepped care and care as usual. Baseline assessment and randomization occurred during pretransplant hospitalization. Stepped care was initiated after 6 weeks, consisting of (1) watchful waiting, (2) Internetbased self-help intervention, and (3) face-to-face counseling/ psychopharmacological treatment/ referral. Follow-up measurements were conducted at 13,30 , and 42 weeks after
\end{abstract}

Annemarie M. J. Braamse

a.braamse@vumc.nl

1 Department of Psychiatry and EMGO Institute for Health and Care Research, VU University Medical Center, A.J.Ernststraat 1187, Amsterdam $1081 \mathrm{HL}$, Netherlands

2 Department of Health, Sports \& Welfare/Cluster Nursing, Inholland University of Applied Sciences, Amsterdam, Netherlands

3 Parnassia Psychiatric Institute, The Hague, Netherlands

4 Department of Hematology, VU University Medical Center, Amsterdam, Netherlands

5 Department of Clinical Psychology, VU University, Amsterdam, Netherlands

6 Department of Oncology/Hematology, Isala Clinics, Zwolle, Netherlands

7 Department of Rehabilitation Medicine, VU University Medical Center, Amsterdam, Netherlands transplantation. Stepped care $(n=47)$ and care as usual $(n=$ 48) were comparable on baseline characteristics. The uptake of the intervention was low: 24 patients started with step 1,23 with step 2, and none with step 3. Percentages of distressed patients ranged from 4.1 to $9.7 \%$. Ten percent of patients received external psychological or psychiatric care. No statistically significant differences were found between stepped care and care as usual on psychological distress or physical functioning in intention to treat analyses, nor in per protocol analyses. The stepped care program was not effective in decreasing psychological distress. The low intervention uptake, probably related to the low levels of psychological distress, offers an explanation for this outcome. Future research should take into account patients' specific care needs.

Netherlands Trial Registry identifier: NTR1770.

Keywords Depression - Anxiety · Quality of life · Hematological neoplasms $\cdot$ Hematopoietic stem cell transplantation

\section{Background}

For patients diagnosed with hematological malignancies, autologous stem cell transplantation (auto-SCT) following highdose chemotherapy is a common treatment option. Treatment with auto-SCT generally leads to improved survival, with an overall $60 \%$ probability of surviving 5 years from transplantation [1]. At the same time, auto-SCT survivors are confronted with impairments in their health-related quality of life (QOL) $[2,3]$. Before and shortly after auto-SCT, patients generally face impairments in physical, emotional, and role functioning. Although most patients return to or surpass pre-transplant levels of functioning in subsequent months and 
years, continuous impairments are observed in physical functioning, role functioning, and global QOL $[2,3]$.

A strong predictor of QOL after auto-SCT is the presence of psychological distress $[4,5]$. Psychological distress is a multifactorial concept, encompassing common feelings of vulnerability, sadness, and fears, as well as potentially disabling problems such as depression, anxiety, or social isolation [6]. In the present study, psychological distress is defined as the presence of elevated depressive or anxiety symptoms. Previous research shows large variation in the prevalence of depressive and anxiety symptoms in the period from pre-transplant to 1 year post-transplant. Prevalence rates of 5 to $48 \%$ have been reported for elevated depressive symptoms, and 5 to $45 \%$ for anxiety symptoms [4, 7-10]; the period of initial hospitalization has been pointed at as being most stressful $[10,11]$. Patients with elevated depressive or anxiety symptoms before or during transplantation more often face impaired post-transplant psychological functioning $[4,5,12,13]$ and physical limitations [4].

Problem Solving Treatment is an effective intervention for reducing psychological distress [14], also in cancer survivors [15]. It aims at strengthening patients' selfmanagement skills to solve present and future problems. Patients learn to (a) prioritize problems which matter most to them and which in principle can be solved, (b) analyze the problem and generate alternative solutions, (c) select methods for solution and implement these, and (d) evaluate the results and prepare for the future. This may help patients cope with the challenges they encounter related to disease and treatment. Since psychological distress seems to contribute to impaired QOL after auto-SCT, successful treatment of psychological distress is expected to improve patients' QOL. In delivering treatment for psychological distress, the stepped care approach has been strongly advocated [16]. In this approach, patients start with the least intensive treatment that is most likely to work. Only those patients insufficiently helped by the initial treatment receive more intensive and costly interventions. Stepped care aims at an effective and efficient allocation of therapeutic resources.

In the present study, psychological support, organized according to a stepped care approach, was offered to patients treated with auto-SCT for hematological malignancies. The steps included (1) watchful waiting; (2) Internetbased self-help program, based on the principles of Problem Solving Treatment; and (3) individual face-toface counseling, medication, or referral to other services. We aimed to evaluate the outcome of stepped care on psychological distress and the QOL domain physical functioning. It was hypothesized that stepped care would result in improvement of psychological distress, and thereby in improvement of physical functioning.

\section{Methods}

\section{Design}

In this pragmatic two-armed randomized clinical trial, stepped care was compared with care as usual. An extensive description of the study protocol has been published previously [17]. The study was approved by the Medical Ethics Committees of the participating hospitals: VU University Medical Center, Amsterdam, and Isala Clinics, Zwolle. All procedures followed were in accordance with the ethical standards of the Medical Ethics Committees and with the Helsinki Declaration of 1975, as revised in 2008. The trial was registered in the Netherlands Trial Registry (NTR1770).

\section{Participants and setting}

Patients were recruited from the hematology departments at the two participating hospitals in the Netherlands between August 2009 and April 2013. Eligibility criteria comprised a diagnosis of hematological malignancy (multiple myeloma, (non-)Hodgkin lymphoma, or acute leukemia), scheduled for treatment with high-dose chemotherapy and auto-SCT; age $\geq 18$ years; and life expectation $>3$ months. Exclusion criteria comprised an insufficient command of the Dutch language, and a contraindication for the stepped care approach (e.g., hospitalization in a mental health institute). All participants provided written informed consent.

The majority of patients received follow-up care after auto$\mathrm{SCT}$ at the hospital where they had been transplanted. However, $41 \%$ of the study participants were redirected to their local hospital for follow-up care.

\section{Procedures}

At hospital admission for high-dose chemotherapy and autoSCT, patients who provided informed consent filled in the baseline questionnaire (T0). Subsequently, patients were allocated at random to one of the two study arms: stepped care or care as usual. Stepped care was initiated after a 6-week buffer period, allowing for initial physical recovery. Follow-up measurements were administered by mail at 13 weeks (T13), 30 weeks (T30), and 42 weeks (T42) after transplantation. The design is illustrated in Fig. 1.

Randomization was performed by the second author, who was not involved in data collection and analysis, using a random digit generator. Randomization was stratified for treating hospital (VU University Medical Center vs Isala Clinics) and diagnosis (multiple myeloma vs lymphoma). Patients were informed about their assignment by the first author during the 6-week buffer period. Due to the nature of the intervention, neither patients nor health care providers could be blinded to 
Fig. 1 Design of the randomized clinical trial/CONSORT flow diagram

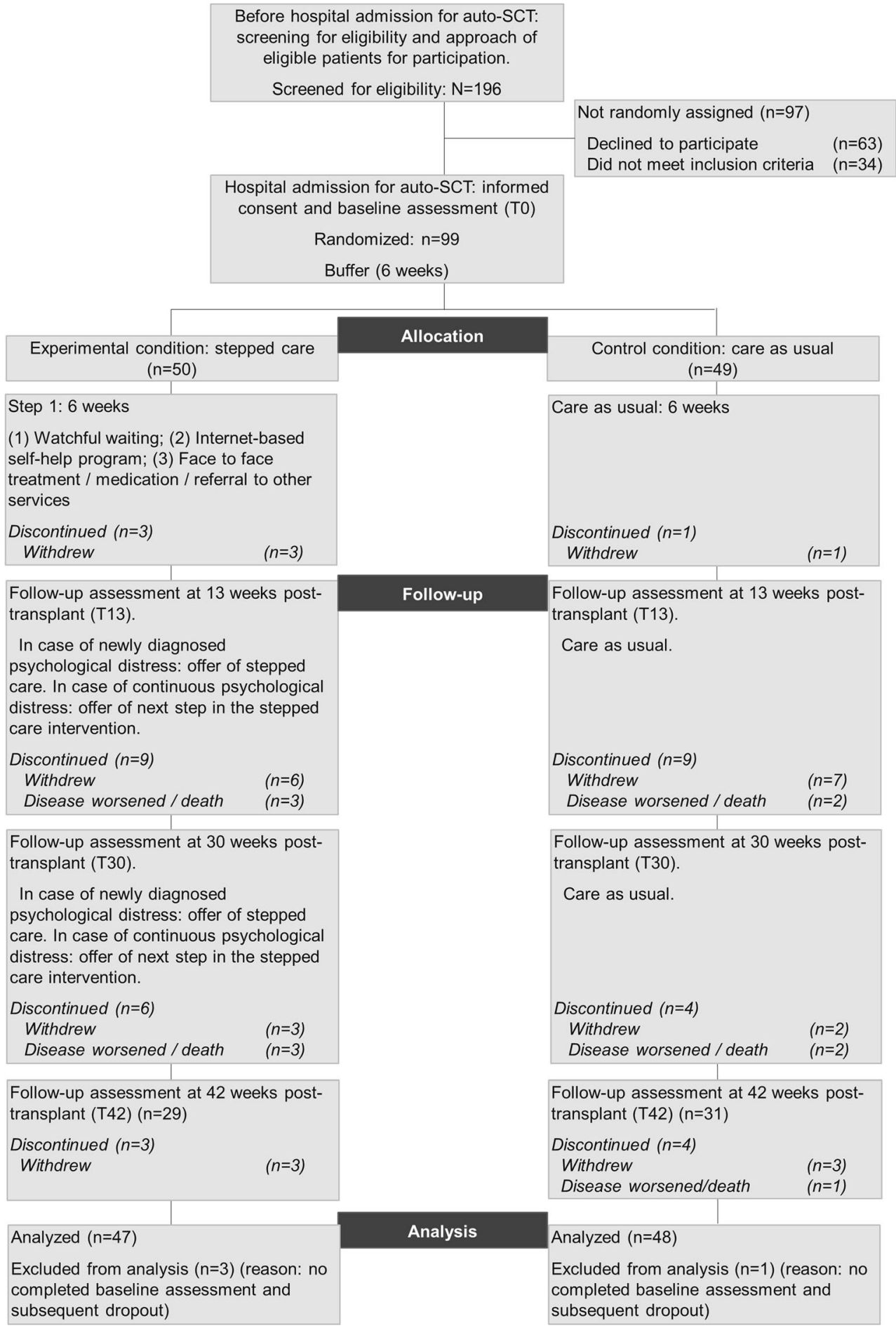

the intervention. Randomization and statistical analysis were performed blindly.

\section{Interventions}

Under the assumption that all patients could benefit from improved problem-solving skills, all patients in the experimental study arm were, regardless of whether psychological distress was present, provided with a stepped care program which contained three steps: watchful waiting, an Internet-based self-help intervention, and individual face-to-face counseling/psychopharmacological treatment/referral to other services (see below). At time of the randomization assignment, patients were asked with which step they wanted to start. Step 1 (watchful waiting) was the default choice, but patients were allowed to start with step 2 or 3 if they wished 
to. At 13- and 30-week follow-up, patients with elevated psychological distress were contacted and asked if they wanted to progress to a next step in the stepped care program.

Step 1: Watchful waiting Since psychological distress often improves without requiring active intervention, the first step consisted of 6 weeks of watchful waiting. This step was added to the study protocol [17], as we noticed during the study that there was a need for a less intensive program option: For some patients, the Internet-based self-help intervention appeared to be too intensive as the default first step of the program. Therefore, we made the program more broadly accessible by adding watchful waiting. At that point in time, 30 patients had already been included in the study, of which 15 patients had been randomly allocated to stepped care. Before adding this step to the protocol, step 2 (Internet-based self-help intervention) was the default choice.

Step 2: Internet-based self-help intervention Patients were provided with an Internet-based self-help intervention, based on the principles of Problem Solving Treatment. Previous studies confirmed the effectiveness of this intervention in treating psychological distress $[18,19]$. The original intervention, called Everything Under Control [18], was adapted to our patient group [17] in close collaboration with nurses, nurse practitioners, and hematologist-oncologists from the Department of Hematology: Specific information on disease and treatment was added, and texts and examples were adjusted to make sure these applied to auto-SCT patients. The intervention consisted of five modules with information, examples, and exercises. Patients were asked to work through one module a week, with the advice to spend approximately $2 \mathrm{~h}$ per module, and send their completed assignments to their coach. Support was provided by a trained psychologist and consisted of brief, weekly e-mails in reply to patients' assignments and a weekly standardized e-mail to announce a new module. Support was merely intended to facilitate patients' effective use of the intervention. Patients could contact their coach at any moment for additional support via e-mail or the website. A small pilot test $(n=3)$ was carried out before the start of the study to ensure applicability and feasibility of the intervention. For patients without access to the Internet, the intervention was available in booklet. The content of the booklet was exactly similar to the website. In these cases, coaching was arranged via telephone or e-mail.

Step 3: Individual face-to-face counseling, psychopharmacological treatment, or referral to other services For patients in step 3, a collaborative care team consisting of a consultant psychiatrist, psychiatric nurse consultant, nurse practitioner (Department of Hematology), hematologist-oncologist, and patient was formed. This team, coordinated by the nurse practitioner, evaluated the patient's need for treatment and developed a treatment plan. Diagnostic evaluation was performed by the consultant psychiatrist, psychiatric nurse consultant, and nurse practitioner, using the following instruments: the anxiety and depression modules of the Composite International Diagnostic Interview (CIDI), version 2.1 [20], Camberwell Assessment of Need (CAN) [21], and Intermed [22]. Subsequently, the psychiatric nurse consultant discussed the following treatment options with the patient: individual face-to-face counseling based on the principles of Problem Solving Treatment, psychopharmacological treatment, and referral to other health care or social services.

In the control condition of the study, patients were provided with care as usual. Care as usual represented regular care at the Department of Hematology in the two hospitals. During regular follow-up visits, emotional support was provided by the hematologist-oncologists and nurses on an ad hoc basis. If patients brought up any problem, hematologist-oncologists or nurses could undertake action and/or refer patients to other services.

\section{Measures}

The following validated and reliable self-report questionnaires were included in the assessment battery: Hospital Anxiety and Depression Scale (HADS) [23], European Organization for Research and Treatment of Cancer Quality of Life Questionnaire-C30 (EORTC QLQ-C30) [24] version 3.0, Patient Health Questionnaire-9 (PHQ-9) [25], Spielberger State-Trait Anxiety Inventory: state version (STAI-state) [26, 27], Social Problem Solving Inventory-Revised (SPSI-R) [28], and the Dutch General Self-efficacy Scale (DGSS) [29]. A checklist, specifically developed for this trial, was used to collect data on additional supportive care patients received. Demographic information was collected at baseline, and medical data were extracted from the patient's medical record. To determine whether elevated psychological distress was present, we used the HADS (cutoff $\geq 8$ on one or both of the subscales, or $\geq 15$ on the overall questionnaire), PHQ-9 (cutoff $\geq 10$ ), and STAI-state (cutoff $\geq 40$ ).

The primary outcomes of the current study were psychological distress (anxiety and depression) (HADS), and physical functioning (EORTC QLQ-C30). Secondary outcomes included emotional functioning and role functioning (EORTC QLQ-C30), other measures of psychological distress (STAI, PHQ), problem solving (SPSI-R), and self-efficacy (DGSS).

\section{Data analysis}

Descriptive statistics were used to compare baseline characteristics of the experimental and control group, and to compare baseline characteristics of dropouts and completers in the total sample. Intention-to-treat and per-protocol analyses were conducted. For the intention to treat analyses, linear mixed-model 
analyses were performed to evaluate the difference in outcome (psychological distress, physical functioning, and secondary outcomes) between the experimental group and the control group. A random intercept was used, and condition and time were fixed effects. A group * time interaction was added to the model to test for treatment effects over time. Based on pooled pre-test standard deviations [30], effect sizes were calculated for the estimated differences between T0 and T13, T0 and T30, and T0 and T42, between groups. To test whether baseline level of distress moderated the effect of the intervention in the two groups, a three-way interaction term (baseline distress * group * time) was added to the model. Since linear mixedmodel analysis is able to handle missing observations due to dropout, no additional actions were undertaken for handling missing data.

Two per-protocol analyses were carried out, following the same procedure as in the intention-to-treat analyses. In the first per-protocol analysis, we excluded patients in the experimental group if (a) despite presence of elevated distress after completing watchful waiting or the Internet-based self-help program, they did not enter a next step of the program; or (b) they followed less than four lessons of the Internet-based self-help intervention. In the second analysis, we only included patients who had completed at least four lessons of the Internet-based self-help program. Patients who had received psychological or psychiatric care outside of the study were excluded from both per protocol analyses. Data were analyzed using IBM SPSS statistics version 20.0 (IBM SPSS Statistics for Windows, Armonk, NY).

\section{Sample size}

The power calculation concerned the comparison at T30 compared to T0 between the two groups (stepped care vs. care as usual). A meta-analysis on Problem Solving Therapy for mental and physical health problems has documented an effect size of $d=0.54$, compared to treatment as usual [14]. Setting $d=0.5$, alpha $=0.05$ (two tail), and beta $=0.80$, the required sample size was $2 \times 64=128$ patients. A second power calculation was made, considering the difference in treatment effect over time (T0, T13, T30, and T42). Setting the within-subject correlation coefficient (rho) at 0.5 , the required sample size was $2 \times 42=84$ patients.

\section{Results}

Of 162 eligible patients, 99 (response rate $61.1 \%$ ) agreed to participate, provided informed consent, filled in the baseline questionnaire (T0), and were randomly assigned to one of the two treatment arms. The main reason for non-participation was considering participation to take too much energy or effort. Some patients refused study participation in general, and a few patients had no interest in psychosocial research. After randomization, four patients appeared to have completed the baseline questionnaire only partly, and they declined further participation. Data of these patients was therefore not analyzed. Of the remaining 95 patients, $78 \%$ (T13), $66 \%$ (T30), and $63 \%$ (T42) completed the follow-up assessments (Fig. 1).

Table 1 presents the baseline demographic and clinical characteristics of our sample. Patients in the two study arms were comparable. When comparing baseline characteristics of patients who completed the study and patients who dropped out before the last assessment, completers were significantly older and lived with a partner, had multiple myeloma (as opposed to lymphoma), and received high-dose melphalan (HDM) as conditioning regimen more often (all $P<0.05$ ).

Overall, external psychological or psychiatric care (independent of the study) was received by $10.3 \%$ of patients during the study period $(5.9 \%$ at T13, $5.7 \%$ at T30, and $7.4 \%$ at T42).

Of the 47 patients who started with the stepped care program, 24 patients started with step 1 (watchful waiting); 1 patient subsequently entered step 2 because of psychological distress. Twenty-three patients started with step 2 (Internet-based selfhelp intervention), of which 15 entered this step by default, before watchful waiting was added to the program. None of the patients entered step 3 (individual face-to-face counseling, psychopharmacological treatment, or referral). Except for one patient, all patients followed only one step of the stepped care program.

In total, 24 patients took the Internet-based self-help intervention. Ten patients completed the intervention (at least four out of five lessons). Reasons for dropout $(n=14)$ were feeling capable of coping by themselves (nine patients); not wanting to deal with psychosocial aspects of disease and treatment at this point in time (three patients); being too ill to continue (one patient); and feeling that one's problems could not be addressed well enough in a self-help intervention, but not wanting to travel to our hospital for face-to-face counseling (one patient). Dropout was independent of the presence of psychological distress: Of the eight patients with psychological distress who entered step 2, 3 completed the intervention; of the 16 patients without psychological distress, 8 completed the intervention.

In both study arms, HADS total scores were relatively low on all four measurement points. However, the large standard deviations in our sample point to substantial individual differences. Percentages of patients scoring $\geq 15$ ranged from 4.1 to $9.7 \%$. Percentages of distressed patients on the HADS subscales and other questionnaires are presented in Table 2.

The results of the intention to treat analyses are summarized in Tables 3 and 4. Table 3 presents the observed means and standard deviations of the HADS total scores, EORTC physical functioning (primary outcomes), and secondary outcomes. Table 4 summarizes the results of the linear mixed models analyses. Comparing stepped care and care as usual 
Table 1 Sample characteristics

\begin{tabular}{|c|c|c|c|}
\hline & Stepped care $(n=47)$ & Care as usual $(n=48)$ & $P$ value \\
\hline Gender, female, $n(\%)$ & $16(34.0)$ & $14(29.2)$ & 0.61 \\
\hline Age in years, mean (s.d.) & $53.3(8.7)$ & $55.5(8.7)$ & 0.23 \\
\hline BMI, mean (s.d.) & $25.8(4.0)$ & $26.4(3.2)$ & 0.41 \\
\hline Living with partner, yes, $n(\%)^{\mathrm{a}}$ & $33(70.2)$ & $40(85.1)$ & 0.08 \\
\hline Education, $n(\%)^{\mathrm{a}}$ & & & 0.06 \\
\hline$<4$-year college degree & $16(34.0)$ & $25(53.2)$ & \\
\hline$\geq 4$-year college degree & $31(66.0)$ & $22(46.8)$ & \\
\hline Diagnosis, $n(\%)$ & & & 0.77 \\
\hline Non-Hodgkin lymphoma & $19(40.4)$ & $17(35.4)$ & \\
\hline Hodgkin lymphoma & $5(10.6)$ & $4(8.3)$ & \\
\hline Multiple myeloma & $23(48.9)$ & $27(56.3)$ & \\
\hline Type of conditioning, $n(\%)$ & & & 0.36 \\
\hline High-dose melphalan (HDM) & $23(48.9)$ & $28(58.3)$ & \\
\hline BEAM/Z-BEAM & $24(51.1)$ & $19(39.6)$ & \\
\hline Busulfan/cyclofosfamide & - & $1(2.1)$ & \\
\hline Somatic comorbidities, $n(\%)^{\mathrm{a}}$ & & & 0.39 \\
\hline None & $6(12.8)$ & $2(4.3)$ & \\
\hline 1 & $19(40.4)$ & $18(38.3)$ & \\
\hline 2 & $8(17.0)$ & $12(25.5)$ & \\
\hline 3 or more & $14(29.8)$ & $15(31.9)$ & \\
\hline Remission status at time of transplant $\mathrm{t}^{\mathrm{b}}$ & & & 0.85 \\
\hline Complete remission & $19(44.2)$ & $19(42.2)$ & \\
\hline Not in complete remission & $24(55.8)$ & $26(57.8)$ & \\
\hline
\end{tabular}

${ }^{\text {a }}$ Care as usual: 1 patient missing data

${ }^{\mathrm{b}}$ Stepped care: 4 patients missing data; care as usual: 3 patients missing data

Table 2 Percentages of patients with psychological distress

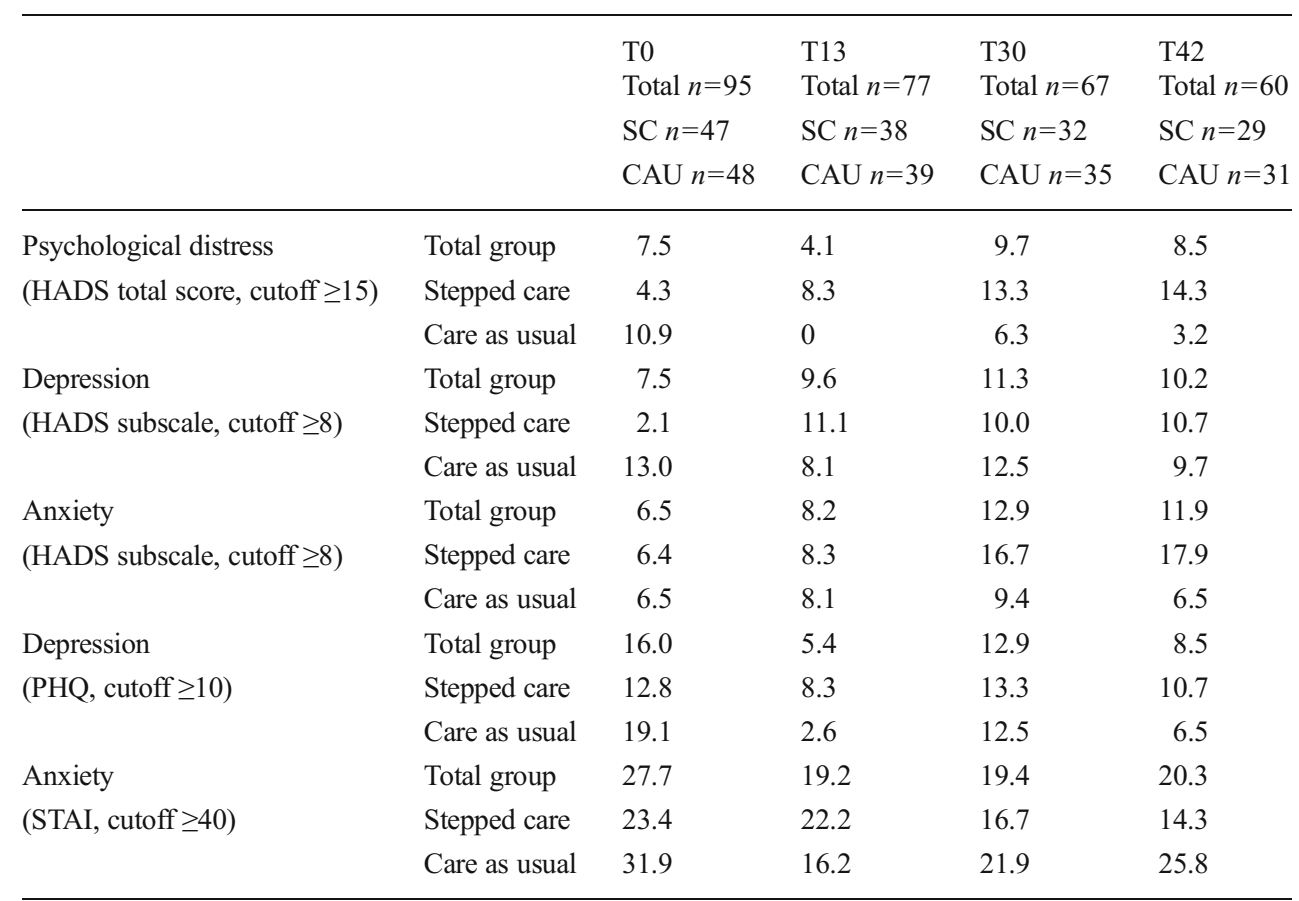

$S C$ stepped care, $C A U$ care as usual, HADS Hospital Anxiety and Depression Scale, $P H Q$ Patient Health Questionnaire, STAI Spielberger State-Trait Anxiety Inventory 
Table 3 Observed mean scores of primary and secondary outcomes

\begin{tabular}{|c|c|c|c|}
\hline & & $\begin{array}{l}\text { Stepped care } N=47 \\
\text { Mean (s.d.) }\end{array}$ & $\begin{array}{l}\text { Care as usual } N=48 \\
\text { Mean (s.d.) }\end{array}$ \\
\hline \multicolumn{4}{|l|}{ Primary outcomes } \\
\hline \multirow{4}{*}{$\begin{array}{l}\text { Psychological distress } \\
\text { (HADS total score) }\end{array}$} & $\mathrm{T} 0$ & $6.72(4.47)$ & $7.26(4.90)$ \\
\hline & $\mathrm{T} 13$ & $6.69(4.96)$ & $5.75(3.45)$ \\
\hline & $\mathrm{T} 30$ & $6.53(6.06)$ & $6.38(5.93)$ \\
\hline & $\mathrm{T} 42$ & $6.54(6.44)$ & $6.29(4.55)$ \\
\hline \multirow{4}{*}{$\begin{array}{l}\text { Depression } \\
\text { (HADS subscale) }\end{array}$} & T0 & $2.98(2.24)$ & $3.52(3.38)$ \\
\hline & $\mathrm{T} 13$ & $3.17(2.55)$ & $2.73(2.51)$ \\
\hline & $\mathrm{T} 30$ & $2.63(2.91)$ & $3.13(4.03)$ \\
\hline & $\mathrm{T} 42$ & $2.64(2.88)$ & $2.87(3.03)$ \\
\hline \multirow{4}{*}{$\begin{array}{l}\text { Anxiety } \\
\text { (HADS subscale) }\end{array}$} & T0 & $3.74(2.88)$ & $3.74(2.64)$ \\
\hline & T13 & $3.53(2.89)$ & $3.03(2.21)$ \\
\hline & $\mathrm{T} 30$ & $3.90(3.58)$ & $3.25(2.75)$ \\
\hline & $\mathrm{T} 42$ & $3.89(3.93)$ & $3.42(2.43)$ \\
\hline \multirow{4}{*}{$\begin{array}{l}\text { Physical functioning } \\
\text { (EORTC QLQ-C30) }\end{array}$} & T0 & $74.47(20.06)$ & $70.64(19.59)$ \\
\hline & $\mathrm{T} 13$ & $74.25(21.91)$ & $74.05(19.55)$ \\
\hline & $\mathrm{T} 30$ & $82.22(17.00)$ & $79.79(23.74)$ \\
\hline & $\mathrm{T} 42$ & $83.10(15.76)$ & $82.80(18.28)$ \\
\hline \multicolumn{4}{|l|}{ Secondary outcomes } \\
\hline \multirow{4}{*}{$\begin{array}{l}\text { Emotional functioning } \\
\text { (EORTC QLQ-C30) }\end{array}$} & T0 & $80.50(17.83)$ & $79.89(16.16)$ \\
\hline & $\mathrm{T} 13$ & $82.41(16.64)$ & $87.84(13.55)$ \\
\hline & $\mathrm{T} 30$ & $84.17(17.28)$ & $84.38(14.93)$ \\
\hline & $\mathrm{T} 42$ & $83.93(17.85)$ & $81.18(14.59)$ \\
\hline \multirow{4}{*}{$\begin{array}{l}\text { Role functioning } \\
\text { (EORTC QLQ-C30) }\end{array}$} & T0 & $59.22(35.24)$ & $57.09(34.18)$ \\
\hline & $\mathrm{T} 13$ & $68.06(28.56)$ & $66.67(24.46)$ \\
\hline & $\mathrm{T} 30$ & $75.00(27.60)$ & $75.52(29.63)$ \\
\hline & $\mathrm{T} 42$ & $74.40(27.02)$ & $74.19(27.50)$ \\
\hline \multirow{4}{*}{$\begin{array}{l}\text { Anxiety } \\
\text { (STAI) }\end{array}$} & T0 & $35.06(8.74)$ & $35.15(8.18)$ \\
\hline & $\mathrm{T} 13$ & $32.97(8.76)$ & $31.57(7.90)$ \\
\hline & $\mathrm{T} 30$ & $32.60(10.22)$ & $33.44(10.33)$ \\
\hline & $\mathrm{T} 42$ & $32.89(11.93)$ & $33.10(9.69)$ \\
\hline \multirow{4}{*}{$\begin{array}{l}\text { Depression } \\
\text { (PHQ) }\end{array}$} & T0 & $5.66(4.07)$ & $4.87(4.96)$ \\
\hline & $\mathrm{T} 13$ & $4.61(3.72)$ & $3.82(2.65)$ \\
\hline & $\mathrm{T} 30$ & $3.93(4.16)$ & $4.84(5.73)$ \\
\hline & $\mathrm{T} 42$ & $4.14(3.66)$ & $3.68(3.45)$ \\
\hline \multirow{4}{*}{$\begin{array}{l}\text { Problem solving } \\
\text { (SPSI-R) }\end{array}$} & T0 & $133.36(19.86)$ & 137.34 (18.36) \\
\hline & $\mathrm{T} 13$ & $138.86(12.43)$ & $135.56(20.92)$ \\
\hline & $\mathrm{T} 30$ & $137.48(14.11)$ & 139.25 (17.29) \\
\hline & $\mathrm{T} 42$ & $140.41(17.46)$ & $136.63(18.58)$ \\
\hline \multirow{4}{*}{$\begin{array}{l}\text { Self-efficacy } \\
\text { (DGSS) }\end{array}$} & T0 & $31.79(3.92)$ & $32.20(5.28)$ \\
\hline & $\mathrm{T} 13$ & $33.28(4.42)$ & $32.38(4.95)$ \\
\hline & $\mathrm{T} 30$ & $33.17(4.15)$ & $31.94(5.10)$ \\
\hline & $\mathrm{T} 42$ & 33.07 (4.95) & 31.57 (6.04) \\
\hline
\end{tabular}

HADS Hospital Anxiety and Depression Scale, EORTC QLQ-C30 European Organization for Research and Treatment of Cancer Quality of Life Questionnaire-C30, SPSI-R Social Problem Solving Inventory-Revised, DGSS Dutch General Self-efficacy Scale, $P H Q$ Patient Health Questionnaire, STAI Spielberger State-Trait Anxiety Inventory

on the HADS total scores and EORTC physical functioning, no statistically significant differences were found. Baseline
Table 4 Test statistics and effect sizes of the differences in primary and secondary outcomes between the experimental group and the control group, from linear mixed model analyses

\begin{tabular}{|c|c|c|c|c|}
\hline & & $t$ & $P$ & Effect size \\
\hline \multicolumn{5}{|l|}{ Primary outcomes } \\
\hline \multirow{3}{*}{$\begin{array}{l}\text { Psychological distress } \\
\text { (HADS total score) }\end{array}$} & Condition*T13 & 1.40 & 0.16 & 0.28 \\
\hline & Condition*T30 & 0.47 & 0.64 & 0.10 \\
\hline & Condition*T42 & 0.50 & 0.62 & 0.11 \\
\hline \multirow{3}{*}{$\begin{array}{l}\text { Depression } \\
\text { (HADS subscale) }\end{array}$} & Condition*T13 & 1.31 & 0.19 & 0.30 \\
\hline & Condition*T30 & -0.10 & 0.92 & -0.02 \\
\hline & Condition*T42 & 0.05 & 0.96 & 0.01 \\
\hline \multirow{3}{*}{$\begin{array}{l}\text { Anxiety } \\
\text { (HADS subscale) }\end{array}$} & Condition*T13 & 0.90 & 0.37 & 0.18 \\
\hline & Condition*T30 & 0.97 & 0.33 & 0.21 \\
\hline & Condition*T42 & 0.87 & 0.39 & 0.19 \\
\hline \multirow{3}{*}{$\begin{array}{l}\text { Physical functioning } \\
\text { (EORTC QLQ-C30) }\end{array}$} & Condition*T13 & -1.00 & 0.32 & -0.19 \\
\hline & Condition*T30 & -0.53 & 0.60 & -0.11 \\
\hline & Condition*T42 & -0.12 & 0.91 & -0.02 \\
\hline \multicolumn{5}{|l|}{ Secondary outcomes } \\
\hline \multirow{3}{*}{$\begin{array}{l}\text { Emotional functioning } \\
\text { (EORTC QLQ-C30) }\end{array}$} & Condition*T13 & -2.32 & $0.02 *$ & -0.43 \\
\hline & Condition*T30 & -0.94 & 0.35 & -0.19 \\
\hline & Condition*T42 & 0.12 & 0.91 & 0.02 \\
\hline \multirow{3}{*}{$\begin{array}{l}\text { Role functioning } \\
\text { (EORTC QLQ-C30) }\end{array}$} & Condition*T13 & -0.09 & 0.93 & -0.02 \\
\hline & Condition*T30 & -0.52 & 0.60 & -0.11 \\
\hline & Condition*T42 & 0.15 & 0.89 & 0.03 \\
\hline \multirow{3}{*}{$\begin{array}{l}\text { Anxiety } \\
\text { (STAI) }\end{array}$} & Condition*T13 & 0.99 & 0.33 & 0.21 \\
\hline & Condition*T30 & -0.29 & 0.77 & -0.07 \\
\hline & Condition*T42 & 0.16 & 0.87 & 0.04 \\
\hline \multirow{3}{*}{$\begin{array}{l}\text { Depression } \\
\text { (PHQ) }\end{array}$} & Condition*T13 & 0.09 & 0.93 & 0.02 \\
\hline & Condition*T30 & -1.32 & 0.19 & -0.31 \\
\hline & Condition*T42 & -0.54 & 0.59 & -0.13 \\
\hline \multirow{3}{*}{$\begin{array}{l}\text { Problem-solving } \\
\text { (SPSI-R) }\end{array}$} & Condition*T13 & 1.59 & 0.11 & 0.29 \\
\hline & Condition*T30 & 1.02 & 0.31 & 0.20 \\
\hline & Condition*T42 & 1.61 & 0.11 & 0.32 \\
\hline \multirow{3}{*}{$\begin{array}{l}\text { Self-efficacy } \\
\text { (DGSS) }\end{array}$} & Condition*T13 & 0.99 & 0.33 & 0.19 \\
\hline & Condition* T30 & 1.27 & 0.21 & 0.26 \\
\hline & Condition*T42 & 1.40 & 0.16 & 0.29 \\
\hline
\end{tabular}

HADS Hospital Anxiety and Depression Scale, EORTC QLQ-C30 European Organization for Research and Treatment of Cancer Quality of Life Questionnaire-C30, SPSI-R Social Problem Solving Inventory-Revised, $D G S S$ Dutch General Self-efficacy Scale, $P H Q$ Patient Health Questionnaire, STAI Spielberger State-Trait Anxiety Inventory $* P<0.05$

level of distress did not moderate the effect of the intervention on distress, nor on physical functioning, in the two groups $(P>0.10$ at T13, T30, and T42; data not shown).

On the following secondary outcomes, no statistically significant differences were found between stepped care and care as usual: STAI anxiety, EORTC emotional functioning, EORTC role functioning, PHQ depression, SPSI-R problem solving, and DGSS self-efficacy (except for a significant difference on EORTC emotional functioning at 13 weeks, in 
favor of the care as usual group ( $t=-2.32, P=0.02, d=-0.43)$ ) (Table 4).

The per-protocol analyses yielded similar results as the intention-to-treat analyses, except for the difference on EORTC emotional functioning at 13 weeks: This finding was non-significant in the per-protocol analysis which included only patients who had completed at least four lessons of the Internet-based self-help program.

\section{Discussion}

The purpose of the present study was to evaluate a stepped care program aimed at treating psychological distress and improving QOL in patients with hematological malignancies treated with auto-SCT. The program as presented here was not effective in treating psychological distress in this patient group. The uptake of the program appeared to be very limited.

Few randomized controlled trials have previously evaluated treatment for psychological distress in hematological cancer patients. An Internet-based program for coping with cancer found an effect on fighting spirit, but not on psychological distress [31]. Another intervention was successful in decreasing anxiety during hospitalization [32]. More broadly, in cancer patients, many trials have focused on treating psychological distress. These trials differ substantially with regard to study designs and studied treatments, but in general, smallto-medium effect sizes have been reached [33]. Reflecting on our trial, the response rate of $61.1 \%$ was relatively high. However, the uptake of our intervention was low, which limited the possibility of finding an intervention effect: Of the 47 patients in the experimental condition, only 24 started with the Internet-based self-help intervention. More intensive treatment options (step 3 of the program) were not chosen.

Several factors may explain the low uptake of the intervention program. The first explanation concerns the prevalence of psychological distress. Prevalence rates of elevated anxiety and depressive symptoms at baseline were 6.5 and $7.5 \%$, respectively; these are equal to some, but lower than other rates found in observational studies [4, 7-10]. Mean distress scores in our sample were lower than in a Dutch population sample of persons aged 18-65 years [23]. The low scores and prevalence rates probably indicate a low need for psychological care in our patient group and/or a high standard of usual care, as $10.3 \%$ of our study participants received psychological or psychiatric care outside of the study program. Together, the low uptake of the intervention, low distress scores, and high standard of usual care probably led to a reduced contrast between the experimental group and the control group.

Given patients' life-threatening illness and stressful treatment, we assumed beforehand that improved problem-solving skills could help to decrease psychological distress and improve QOL in all patients. We therefore offered the stepped care program to all patients in the experimental study arm, regardless of their level of psychological distress. This may have limited our potential to show an intervention effect: In recent years, it has become clear that patients with elevated levels of distress are the patients most likely to benefit from psychological interventions $[33,34]$. Trials showing effective treatment results either only included patients with psychological distress (e.g., $[35,36])$ or recruited patients via advertisements [31] and thereby pre-selected study participants with a higher need for and interest in an intervention aimed at psychological distress. However, in our trial, subanalyses with only distressed patients did not show a significant intervention effect. It is suggested that future interventions should target specific care needs, instead of being offered to all patients. In this respect, it is important to note that presence of psychological distress and need for support not necessarily coincide [37]. Besides, whether psychological distress is the best indicator for guiding supportive care is questionable. Targeting care needs could be considered instead [38], in which case a focus on physical and cognitive-emotional needs could be desirable [39]. In addition, cost-effectiveness is an important aspect when implementing interventions and should be evaluated in future studies.

A second factor influencing the uptake of our intervention program could be the nature of the intervention itself. The Internet-based self-help intervention, which was the second step of the program, has previously been shown to be effective [18]. Our dropout rates were relatively high, however. When evaluating the reasons for dropout, the intensity of the program appeared to be too high for those patients who felt capable of coping with their problems themselves. For other patients, the timing of offering the intervention did not match their needs. The third and most intensive step of the program, consisting of face-to-face treatment or other care options, was not chosen by any patient. One interpretation of our results is that Problem Solving Treatment as specific psychotherapeutic technique, as well as the opportunity to receive face-to-face treatment, may not match the needs of the majority of patients. Most hematological cancer patients seem resilient when it comes to coping with their disease and QOL impairments. If needed, other forms of psychological support could be more suitable, such as supporting self-management, or guided peer support, reserving psychotherapeutic care options for those patients with an anxiety or depressive disorder.

Other factors that may have influenced the uptake of the intervention are current health care provision, the timing of offering treatment, and logistic issues. First, during the study period, $10.3 \%$ of the study participants received psychological or psychiatric care outside of the study. This could reflect the relatively high accessibility of additional supportive care in the Dutch health care system. Second, in our stepped care program, providing patients with psychological care options at 6 weeks after transplantation may not have been 
appropriate. Emotional problems might occur at that point in time, but also in an earlier stage of the disease or treatment process or, conversely, in a later stage. It has been proposed that emotional concerns may only come up after acute physical problems have been dealt with [40]. The timing of offering treatment should be flexible, fitting individual patients' needs. Finally, the treatment location in step 3 of the stepped care program may have led to logistic barriers. This step was organized in the hospitals where patients had received their auto-SCT. However, about $40 \%$ of the patients were redirected to their local hospital for follow-up care after auto-SCT.

Concluding, the stepped care program as presented in the current study was not effective in decreasing psychological distress. This could mainly be explained by the low uptake of the intervention, probably because of the low baseline levels of psychological distress. Also, whether psychological distress is the best indicator for guiding supportive care is questionable. Future research could look into treatments that target patients' care needs, and into other ways of support than psychotherapeutic treatment.

Conflict of interest The authors declare that they have no conflict of interest.

Open Access This article is distributed under the terms of the Creative Commons Attribution 4.0 International License (http:// creativecommons.org/licenses/by/4.0/), which permits unrestricted use, distribution, and reproduction in any medium, provided you give appropriate credit to the original author(s) and the source, provide a link to the Creative Commons license, and indicate if changes were made.

\section{References}

1. VanderWalde AM, Sun CL, Laddaran L, Francisco L, Armenian S, Berano-The J, Wong FL et al (2013) Conditional survival and cause-specific mortality after autologous hematopoietic cell transplantation for hematological malignancies. Leukemia 27:11391145

2. Pidala J, Anasetti C, Jim H (2010) Health-related quality of life following hematopoietic stem cell transplantation: patient education, evaluation and intervention. Br J Haematol 148:373-385

3. Mosher CE, Redd WH, Rini CM, Burkhalter JE, DuHamel KN (2009) Physical, psychological, and social sequelae following hematopoietic stem cell transplantation: a review of the literature. Psycho-Oncology 18:113-127

4. Syrjala KL, Langer SL, Abrams JR, Storer B, Sanders JE, Flowers MED et al (2004) Recovery and long-term function after hematopoietic cell transplantation for leukemia or lymphoma. JAMA 291(19):2335-2343

5. Andorsky DJ, Loberiza FR, Lee SJ (2006) Pre-transplantation physical and mental functioning is strongly associated with selfreported recovery from stem cell transplantation. Bone Marrow Transplant 37(9):889-895

6. National Comprehensive Cancer Network I (2002). Practice guidelines in oncology: distress management. Version 1. National Comprehensive Cancer Network, Inc
7. Hoodin F, Zhao L, Carey J, Levine JE, Kitko C (2013) Impact of psychological screening on routine outpatient care of hematopoietic cell transplantation survivors. Biol Blood Marrow Transplant 19: 1493-1497

8. Pillay B, Lee SJ, Katona L, De Bono S, Burney S, Avery S (2014) A prospective study of the relationship between sense of coherence, depression, anxiety, and quality of life of haematopoietic stem cell transplant patients over time. Psychooncology. doi:10.1002/pon. 3633

9. Sherman AC, Simonton S, Latif U, Plante TG, Anaissie EJ (2009) Changes in quality-of-life and psychosocial adjustment among multiple myeloma patients treated with high-dose melphalan and autologous stem cell transplantation. Biol Blood Marrow Transplant 15(1):12-20

10. Prieto JM, Blanch J, Atala J, Carreras E, Rovira M, Cirera E, Gastó C (2002) Psychiatric morbidity and impact on hospital length of stay among hematologic cancer patients receiving stem cell transplantation. J Clin Oncol 20(7):1907-1917

11. Fife BL, Huster GA, Cornetta KG, Kennedy VN, Akard LP, Broun ER (2000) Longitudinal study of adaptation to the stress of bone marrow transplantation. J Clin Oncol 18(7):1539-1549

12. Lee SJ, Loberiza FR, Antin JH, Kirkpatrick T, Prokop L, Alyea EP et al (2005) Routine screening for psychosocial distress following hematopoietic stem cell transplantation. Bone Marrow Transplant $35: 77-83$

13. Schulz-Kindermann F, Hennings U, Ramm G, Zander AR, Hasenbring M (2002) The role of biomedical and psychosocial factors for the prediction of pain and distress in patients undergoing high-dose therapy and BMT/PBSCT. Bone Marrow Transplant 29: 341-351

14. Malouff JM, Thorsteinsson EB, Schutte NS (2007) The efficacy of problem solving therapy in reducing mental and physical health problems: a meta-analysis. Clin Psychol Rev 27(1):46-57

15. Osborn RL, Demoncada AC, Feuerstein M (2006) Psychosocial interventions for depression, anxiety, and quality of life in cancer survivors: meta-analyses. Int J Psychiatry Med 36(1):13-34

16. Bower P, Gilbody S (2005) Stepped care in psychological therapies: access, effectiveness and efficiency. Narrative literature review. Br J Psychiatry 186:11-17

17. Braamse AM, van Meijel B, Visser O, van Oppen P, Boenink AD, Eeltink C, Cuijpers P, Huijgens PC, Beekman AT, Dekker J (2010) Distress and quality of life after autologous stem cell transplantation: a randomized clinical trial to evaluate the outcome of a webbased stepped care intervention. BMC Cancer 7(10):361

18. Van Straten A, Cuijpers P, Smits N (2008) Effectiveness of a webbased self-help intervention for symptoms of depression, anxiety, and stress: randomized controlled trial. J Med Internet Res 10(1):e7

19. Cuijpers P, van Straten A, Warmerdam L (2007) Problem solving therapies for depression: a meta-analysis. Eur Psychiatry 22(1):915

20. World Health Organization (1997) Composite International Diagnostic Interview (CIDI), version 2.1. WHO, Geneva

21. Phelan M, Slade M, Thornicroft G, Dunn G, Holloway F, Wykes T et al (1995) The Camberwell Assessment of Need: the validity and reliability of an instrument to assess the needs of people with severe mental illness. Br J Psychiatry 167(5):589-595

22. De Jonge P, Huyse FJ, Stiefel FC, Slaets JP, Gans RO (2001) INTERMED - a clinical instrument for biopsychosocial assessment. Psychosomatics 42(2):106-109

23. Spinhoven P, Ormel J, Sloekers PP, Kempen GI, Speckens AE, van Hemert AM (1997) A validation study of the Hospital Anxiety and Depression Scale (HADS) in different groups of Dutch subjects. Psychol Med 27(2):363-370

24. Aaronson NK, Ahmedzai S, Bergman B, Bullinger M, Cull A, Duez NJ et al (1993) The European Organization for Research and Treatment of Cancer QLQ-C30: a quality-of-life instrument 
for use in international clinical trials in oncology. J Natl Cancer Inst 85(5):365-376

25. Kroenke K, Spitzer RL, Williams JB (2001) The PHQ-9: validity of a brief depression severity measure. J Gen Intern Med 16(9):606-613

26. Van der Ploeg H (1980) Validity of the Zelf-BeoordelingsVragenlijst (a Dutch version of the Spielberger State-Trait Anxiety Inventory). Nederlands Tijdschrift Psychologie Haar Grensgebieden 35:243-249

27. Spielberger CD, Gorsuch RL, Lushene RE (1970) Manual for the State-Trait Anxiety Inventory. Consulting Psychologists Press, Palo Alto

28. D'Zurilla T, Nezu A, Maydeu-Olivares A (2002) Social ProblemSolving Inventory-Revised (SPSI-R): Manual. Multi-Health Systems, North Tonawanda

29. Luszczynska A, Scholz U, Schwarzer R (2005) The general selfefficacy scale: multicultural validation studies. J Psychol 139(5): 439-457

30. Morris SB (2008) Estimating effect sizes from pretest-posttestcontrol group designs. Organ Res Methods 11(2):364-386

31. David N, Schlenker P, Prudlo U, Larbig W (2013) Internet-based program for coping with cancer: a randomized controlled trial with hematologic cancer patients. Psycho-Oncology 22:1064-1072

32. McCabe C, Roche D, Hegarty F, McCann S (2013) 'Open Window': a randomized trial of the effect of new media art using a virtual window on quality of life in patients' experiencing stem cell transplantation. Psycho-Oncology 22:330-337

33. Faller H, Schuler M, Richard M, Heckl U, Weis J, Küffner R (2013) Effects of psycho-oncologic interventions on emotional distress and quality of life in adult patients with cancer: systematic review and meta-analysis. J Clin Oncol 31(6):782-793

34. Schneider S, Moyer A, Knapp-Oliver S, Sohl S, Cannella D, Targhetta V (2010) Pre-intervention distress moderates the efficacy of psychosocial treatment for cancer patients: a meta-analysis. $\mathrm{J}$ Behav Med 33(1):1-14

35. Fann JR, Fan MY, Unutzer J (2009) Improving primary care for older adults with cancer and depression. J Gen Intern Med 24(suppl 2):S417-S424

36. Kroenke $\mathrm{K}$, Theobald $\mathrm{D}$, Wu J, Norton $\mathrm{K}$, Morrison G, Carpenter J et al (2010) Effect of telecare management on pain and depression in patients with cancer: a randomized trial. JAMA 304:163-171

37. van Scheppingen C, Schroevers MJ, Smink A, van der Linden YM, Mul VE, Langendijk JA et al (2011) Does screening for distress efficiently uncover meetable unmet needs in cancer patients? Psycho-Oncology 20:655-663

38. Carey M, Lambert S, Smits R, Paul C, Sanson-Fisher R, ClintonMcHarg T (2012) The unfulfilled promise: a systematic review of interventions to reduce the unmet supportive care needs of cancer patients. Support Care Cancer 20:207-219

39. Braamse AM, van Meijel B, Visser O, Huijgens PC, Beekman AT, Dekker J (2014) Distress, problems, and supportive care needs of patients treated with auto- or allo-SCT. Bone Marrow Transplant 49(2):292-298

40. Bevans M (2010) Health-related quality of life following allogeneic hematopoietic stem cell transplantation. Hematology Am Soc Hermatol Educ Program 2010:248-254 